\title{
Effects of comprehensive sexuality education on the comprehensive knowledge and attitude to condom use among first-year students in Arba Minch University: a quasi-experimental study
}

Negussie Boti ${ }^{1 *}$, Sultan Hussen ${ }^{1}$, Mulugeta Shegaze ${ }^{1}$, Simon Shibru ${ }^{3}$ Tamiru Shibiru², Eshetu Zerihun', Wanzahun Godana', Sintayehu Abebe ${ }^{1}$, Woyinshet Gebretsadik ${ }^{4}$, Nathan Desalegn ${ }^{4}$ and Zebene Temtime ${ }^{5}$

\begin{abstract}
Objective: To assess the effect of comprehensive sexuality education on the comprehensive knowledge and attitude to condom use among first-year students at Arba Minch University.

Results: A total of 832 students participated at a baseline, and 820 students participated at the posttest. This study found that there was a significant effect on changing students' knowledge and attitude towards a condom. In the education group, the students' average change of comprehensive condom knowledge score was 0.229 higher than the average score of students' in the control group (ATE $=0.229,95 \% \mathrm{Cl} 0.132$ to $0.328 ; \mathrm{p}<0.001$ ). The average change of attitude toward condom score of students' in the education group was 1.834 higher than the average change score of students' in the control group (ATE $=1.834,95 \% \mathrm{Cl} 1.195$ to 2.772; $\mathrm{p}<0.001$ ). This study provides further evidence on the effectiveness of comprehensive sexuality education in terms of knowledge and attitude towards a condom. Therefore, the implementation of this education should be strengthened in order the prevent youths from STI/HIV and unintended pregnancies.
\end{abstract}

Keywords: Comprehensive sexuality education, Knowledge to condom, Attitude to condom: intention to condom use, University student: Ethiopia

\section{Introduction}

According to the world health organization (WHO) Youth is an important population group with great potential for physical, mental, and psychological development [1]. Youths are the largest population there were 1.80 billion people between the ages of 10 and 24 years, of the $70 \%$ are concentrated in developing countries [2]. In Ethiopia from the total population, $20.04 \%$ were between 15 and 24 years $[3,4]$. Most of them are joining a higher

*Correspondence: Hanehalid@gmail.com

${ }^{1}$ College of Medicine \& Health Sciences, Department of Public Health, Arba Minch University, Arba Minch, Ethiopia

Full list of author information is available at the end of the article institution for an academic program [5, 6]. Higher education institutions in Ethiopia host young people aged between 19 and 24 years $[7,8]$.

According to reports shows that worldwide youths were at high risk of HIV infection, accounting for $20 \%$ of new HIV infections [7, 9]. Seventy-nine percent of these infections occur in Sub-Saharan Africa (SSA) [7]. Also, each year 7.4 million girls experienced unintended pregnancies and 3 million girls experienced unsafe abortions [10]. These problems put young people at risk for morbidity, mortality and limiting their educational and employment opportunities [11,12].

Evidence shows that higher education institutions are the best place to deal with sexual reproductive health 
problem including HIV/AIDS and unintended pregnancy [11]. Ethiopia started sexual and reproductive health prevention information and services accessible to higher learning institutions Since 2008 [2, 4].

Even though, comprehensive sexuality education is implemented in Ethiopia as one of the sexual and reproductive health-related problems prevention and control strategies among higher institution youth in Ethiopia including the study area. However, the effect of this education was not assessed previously in Ethiopia. Therefore, this study aims to assess the effect of an education intervention on knowledge and attitude towards a condom among first-year students of Arba Minch University in $2017 / 18$

\section{Main text \\ Methods \\ Study design and setting}

A quasi-experimental study was conducted among firstyear students of Arba Minch University.

\section{Population}

All first-year students of Arba Minch University in regular programs were the source population whereas all first-year students in selected departments who attend regular programs and full fill inclusion criteria in both intervention and control groups were study population.

\section{Inclusion and exclusion criterion (eligibility criteria)}

The study included all first-year students whose ages between 15 and 24 years, but those students who had previous exposure for comprehensive sexuality education and those who have unable to respond due to severe illness were excluded from the study.

\section{Sample size determination}

The required sample size for the number of students needed for this study was calculated by Open Statcalc based on the following assumptions: Based on the study done in Lusaka, Zambia, the proportion of students who used condom consistently and correctly with casual partner last time among control group was $59.1 \%$ and among intervention group was $71.4 \%$ [13]. At a $95 \%$ confidence interval for a two-sided test, power of $80 \%$, a minimum detectable alternative of $\pm 5 \%$. Accordingly, the calculated sample size was 504 participants. Assuming a study refusal rate of $10 \%$ and a design effect of 1.5 , a total minimum sample size needed for this study was $504^{*}$ $0.1+504=554^{*} 1.5=832$ individuals.

\section{Sampling technique}

The sampling procedure used in this study was cluster sampling techniques. The sampling frame used for this study was obtained from Arba Minch University registrar office. Arba Minch University geographical located in two towns administrative of zone. The Arba Minch and sawla town. Those towns used as clusters. To select the samples of departments, departments were stratified into two clusters and samples of students were selected independently in each cluster in two stages. In the first stage, a total of 16 departments (8 from each cluster) were selected with purposively and with independent selection in each sampling stratum. In the second stage of selection, a fixed number of 832 ( 416 per cluster) were selected using simple random sampling techniques using a computer-generated random table (Fig. 1).

\section{Measurement}

Knowledge towards condoms was measured using four items developed after reviewing previously done literature. The scale is comprised of the following question, having heard about the male and female condom, condoms are an effective method to prevent unwanted pregnancy, HIV/AIDS and sexually transmitted infection (STI). The correct answers were coded " 1 " and wrong answers "0" [14].

Attitude towards condoms was measured using thirty Likert scale items developed after reviewing previously done pieces of literature [14-16]. Respondents were presented with the following statements. Response categories included: $1=$ agree, $2=$ not sure and $3=$ disagree.

Intention to use a condom was measured based on the study subjects responses to the question asked on regardless of their past sexual experience the students were assessed for their intention to use a condom in their next sexual encounter, using the following item: "I intend to use a condom at the next sexual intercourse." Responses were arranged from strongly agree to strongly disagree on a 5-point scale. This variable will be treated as continuous and each variable coded as "1" or Have great intention to use condoms If the study subject responded as he/she intend to use a condom at the next sexual intercourse and "0" or student don't have an intention to use condoms $[3,17]$.

\section{Data collection procedure}

Data were collected using a self-administered questionnaire. The questionnaire was initially adopted from the WHO knowledge, attitudes, beliefs, and practices survey instrument and further modified based on available literatures $[14,18-20]$. At the pre-intervention stage, the baseline information for respondents was obtained from two groups (intervention and control group) 1 week before starting an educational intervention. The unique confidential identification number was assigned to each student to allow for matching their responses across time points. This was followed by an intervention stage in 


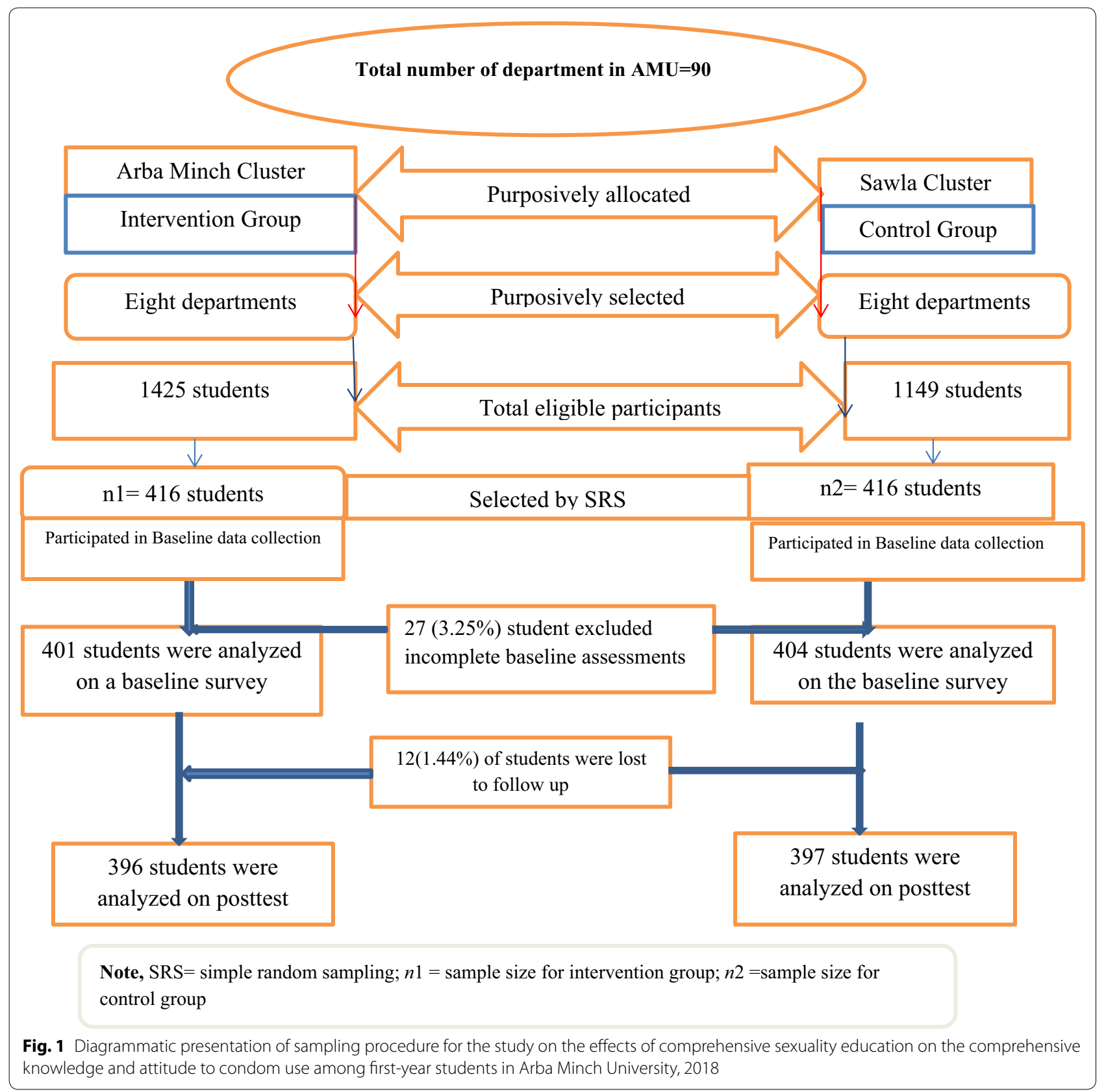

which a series of 16-week education sessions for students in the intervention group which was designed to equip students with knowledge, skills, and attitudes needed to prevent SRH problems and bring positive behavioral changes on sexual and reproductive issues. The education was delivered using brainstorming, lectures, case study, discussion and demonstrations methods. Immediately, after the last education session before the final exam, the post-intervention stage, the same questionnaire that used in the pre-intervention stage was administered to the same students who were selected at the pre-intervention stage in both the intervention and the control groups.

\section{Data quality control}

To data quality control training was given for data collectors and data clerk personnel. Intensive supervision was done by investigators during data collection. A pretest was conducted at Arba Minch Health Science College that was equivalent to $5 \%$ of the study participants to check the accuracy and consistency of the data collection tools. All the data were cleaned double entered and cross-checked for their completeness and linkage to the unique identification number before analysis. The database was checked for incorrect or out of range data entry. 


\section{Data analysis}

The completeness and consistency of the data were checked, coded and double entered into Epi-data 3.1 and exported to STATA version 14.0 statistical software for further analysis. Descriptive statistics were performed. Pearson's Chi squared test was used to compare categorical outcome variables before and after intervention as well as between the intervention and control group. Furthermore, to compare continuous outcome variables before and after the intervention was tested using paired t-tests while differences between the control group and the intervention groups were tested using the independent $\mathrm{t}$-test. To see the effect of intervention we used an inverse probability weighted (IPW) analysis.

\section{Results}

Socio-demographic characteristics of the study participants A total of 416 questionnaires were administered to each study group and control group at the pre-intervention stage of the study. Among those 401 and 404 questionnaires were filled, giving the response rate of $96.75 \%$. At the post-intervention stage, 411 and 409 questionnaires were administered to intervention (education) and control (without education) group, respectively. Among those 396 and 397 questionnaires were filled at this stage giving the response rate of $96.71 \%$. Furthermore, the education and control group were properly matched such that there was no statistically significant difference in their socio-demographic characteristics of respondents (Table 1 ).

\section{Comparison of pre-test and post-test scores in both the education and control groups}

From paired t-test analysis, it was found out that there were significant differences in pre-test and post-test mean scores of comprehensive knowledge on condoms of the respondents in the intervention group $(\mathrm{p}=0.001)$. While among the respondents in the

Table 1 Socio-demographic characteristics of the study participants in Arba Minch University, Ethiopia, 2018/19

\begin{tabular}{|c|c|c|c|c|c|}
\hline Study group & Variables & Subcategories & Pre-intervention N (\%) & $\begin{array}{l}\text { Post- } \\
\text { intervention } \\
\mathrm{N}(\%)\end{array}$ & p-value \\
\hline \multirow[t]{14}{*}{ Intervention group } & \multirow[t]{2}{*}{ Sex } & Male & $297(74.1)$ & $294(74.2)$ & \multirow{3}{*}{$\begin{array}{l}X^{2}=0.206 \\
p=0.694\end{array}$} \\
\hline & & Female & $104(25.9)$ & $102(25.8)$ & \\
\hline & Age in year & Mean $\pm S D$ & $19.55 \pm 1.94$ & $19.60 \pm 1.14$ & \\
\hline & \multirow[t]{5}{*}{ Religion } & Orthodox & $259(64.6)$ & $256(64.6)$ & \multirow{5}{*}{$\begin{array}{l}X^{2}=7.39 \\
p=0.807\end{array}$} \\
\hline & & Catholic & $2(0.5)$ & $2(0.5)$ & \\
\hline & & Protestant & $97(24.2)$ & $95(24.0)$ & \\
\hline & & Muslim & $39(9.7)$ & $38(9.6)$ & \\
\hline & & Others & $4(1.0)$ & $5(1.3)$ & \\
\hline & \multirow[t]{2}{*}{ Type of school attended } & Governmental & $348(86.8)$ & $347(87.6)$ & \multirow{2}{*}{$\begin{array}{l}x^{2}=42 \\
p=0.654\end{array}$} \\
\hline & & Private & $53(13.2)$ & $49(12.4)$ & \\
\hline & \multirow[t]{2}{*}{ Participating in religion education } & Yes & $353(88)$ & $367(92.3)$ & \multirow{2}{*}{$\begin{array}{l}x^{2}=0.069 \\
p=1.000\end{array}$} \\
\hline & & No & $48(12)$ & $29(7.3)$ & \\
\hline & \multirow[t]{2}{*}{ Ever discussed Sex-related matters } & Yes & $170(42.4)$ & $236(59.6)$ & \multirow{2}{*}{$\begin{array}{l}X^{2}=0.796 \\
p=0.408\end{array}$} \\
\hline & & No & $231(57.8)$ & $160(40.4)$ & \\
\hline \multirow[t]{14}{*}{ Control group } & \multirow[t]{2}{*}{ Sex } & Male & $250(61.9)$ & $245(61.7)$ & \multirow{3}{*}{$\begin{array}{l}X^{2}=0.58 \\
p=0.595\end{array}$} \\
\hline & & Female & $154(38.1)$ & $152(38.3)$ & \\
\hline & Age in year & Mean \pm SD & $19.67 \pm 126$ & $19.69 \pm 1.17$ & \\
\hline & \multirow[t]{5}{*}{ Religion } & Orthodox & $278(68.8)$ & $275(69.3)$ & \multirow{5}{*}{$\begin{array}{l}X^{2}=9.49 \\
p=0.578\end{array}$} \\
\hline & & Catholic & $8(2)$ & $6(1.5)$ & \\
\hline & & Protestant & $62(15.3)$ & $61(15.4)$ & \\
\hline & & Muslim & $54(13 / 4)$ & $53(13.4)$ & \\
\hline & & Others & $2(0.5)$ & $2(0.5)$ & \\
\hline & \multirow[t]{2}{*}{ Type of school attended } & Governmental & $351(86.9)$ & $349(57.9)$ & \multirow{2}{*}{$\begin{array}{l}X^{2}=1.19 \\
p=0.282\end{array}$} \\
\hline & & Private & $53(13.1)$ & $48(12.1)$ & \\
\hline & \multirow[t]{2}{*}{ Participating in religion education } & Yes & $348(86.1)$ & $307(77.3)$ & \multirow{2}{*}{$\begin{array}{l}X^{2}=1.44 \\
p=0.235\end{array}$} \\
\hline & & No & $56(13.9)$ & $90(22.7)$ & \\
\hline & \multirow[t]{2}{*}{ Ever discussed Sex-related matters } & Yes & $168(41.6)$ & $176(44.3)$ & \multirow{2}{*}{$\begin{array}{l}x^{2}=0.457 \\
p=0.539\end{array}$} \\
\hline & & No & $236(58.4)$ & $221(55.7)$ & \\
\hline
\end{tabular}


control group there are no significant differences in the mean improvement of the scores of Comprehensive knowledge on condoms $(\mathrm{p}=0.967)$. Similarly, finding from paired $t$-test analysis shows that, there were significant differences in the pre-test and post-test scores of attitude toward condoms $(\mathrm{p}=0.006)$ of the respondents in the intervention group compared to the control group. Also, when comparing the baseline and end-line findings of both the intervention and control groups using Chi square test. The proportions of study participants in the intervention group 148 (36.9\%) have the intention to use a condom during pre-intervention and 162 (40.9\%) during post-intervention periods (p-value $=0.001)$.

\section{Comparison between education and control groups after intervention}

The finding of this study reveals that there is significant difference between education and control group after intervention using independent $\mathrm{t}$-test shows that the mean scores between the two groups related to comprehensive knowledge of condom showed that the intervention group had higher scores than the control group with statistically significant differences (mean diff. $=0.221$, $95 \% \mathrm{CI}=0.12$ to $0.32: \mathrm{p}=0.001$ ). Also there is statistically significant differences in students' attitude to condoms (mean diff. $=2.01,95 \% \mathrm{CI}=1.06$ to $2.96: \mathrm{p}=0.001$ ).

\section{Effect of comprehensive sexuality education on knowledge and attitude to condom}

Inverse probability weighting analysis was conducted to see the effect of the comprehensive sexuality education on students' knowledge and attitude towards condom. All outcome variables were weighted by the baseline characteristics of study participants (sex, age, residence, religion, attendance of religious education and type of school they attended) to reduce the effect of selection bias.

In the education group, the student's average change of comprehensive condom knowledge score was 0.229 higher than the average score of the student's in the control group (ATE $=0.229,95 \% \mathrm{CI} 0.132$ to $0.328 ; \mathrm{p}<0.001$ ). The average change of attitude toward condom score of the student's in the education group was 1.834 higher than the average change score of students in the control group (ATE $=1.834,95 \%$ CI 1.195 to $2.772 ; \mathrm{p}<0.001$ ) (Table 2).

\section{Discussion}

Results from the current study found that there is a significant difference between education and control group
Table 2 The effect of comprehensive sexuality education on Sexual behavior among first-year Arba Minch University students, Arba Minch, Ethiopia, 2018/19

\begin{tabular}{llll}
\hline Variables & $\begin{array}{l}\text { Regression } \\
\text { coefficient }\end{array}$ & $\mathbf{9 5 \% ~ C l}$ & p-value \\
\hline $\begin{array}{l}\text { Comprehensive knowledge } \\
\text { about condoms }\end{array}$ & 0.229 & $(0.132,0.328)$ & $<0.001^{*}$ \\
$\begin{array}{l}\text { Attitude toward condoms } \\
\text { Intention to use condoms }\end{array}$ & 1.834 & $(1.195,2.772)$ & $<0.001^{*}$ \\
\hline
\end{tabular}

${ }^{*} p<0.05$ sig. (2-sided)

after intervention on student's comprehensive knowledge and attitude towards condoms. This finding was in line with a study conducted in Los Angeles and Northern Ghana $[19,20]$. This study also supported the 2030 Agenda specific all learners acquire knowledge and skills needed to promote sustainable development [21].

Concerning intention to use condoms, the finding of this study that there were significant differences in the changing students' intention to condom use between the education and control groups after intervention. This finding was supported study conducted in Tanzania, Los Angeles, Zambian and USA [13, 19, 22, 23]. This might be inducted that availing condom around school compound may reduce students from practicing risky sexual behavior that may help the fight against HIV and to Ending the AIDS Epidemic by 2030 [21].

Furthermore, the finding of this study shows that there was no significant difference between the education and control group in the consistent and correct use of condoms after the intervention. This finding was supported by study conduct in Zambian secondary schools which reveal that there was no change in condom use practice after the intervention [13]. But, inconsistent with other studies [14, 24]. Moreover, the previous study suggested that adequate condom related knowledge was not a sufficient determinant to condom use [23]. Furthermore, having information did not have a direct influence on condom use, information indirectly contributed to condom use mediated by behavioral skills $[24,25]$.

\section{Conclusion}

In conclusion, this study found that comprehensive sexuality education improves the students' knowledge and had an impact on their attitude and intentions towards condom use. However, the findings of this study did not show a significant effect on students' consistent and correct use of a condom because this may require time to practice. Therefore, strengthen the implementation of this education should be are necessary for the control and prevention of STI including HIV/AIDS and unintended pregnancy. 


\section{Limitation of the study}

This study may have some limitations. First, the campuses were not randomly assigned to intervention and control groups. Although we tried to match some confounding factors such as social-demographic characters, there may be some unknown factors influencing the effect of intervention, which might increase or decrease the real effect of intervention. Second, the intervention period 6 months may not show the long term impact of this program. Thirdly, we use results from a Zambian study as the basis of your sample size calculation as a limitation in the study that may have interfered with the representativeness of our sample.

\begin{abstract}
Abbreviations
AIDS: acquired, immune deficiency syndrome; ATE: average treatment effect; CMHS: College of Medicine and Health Science; HEls: higher education institutions; HIV: human immuno deficiency virus; IPW: inverse probability weighted; SD: standard deviation; SOP: standard operating procedure; SRH: sexual reproductive health; SRS: simple random sampling; SSA: Sub-Saharan Africa; STI: sexually transmitted infections; WHO: World Health Organization.
\end{abstract}

\section{Acknowledgements}

We would like to acknowledge all study participants for their voluntary participation in this study. We would like to extend our gratitude to Arba Minch University for all the support and opportunity provided for us to conduct this study.

\section{Authors' contributions}

$\mathrm{NB}, \mathrm{SH}$, and MS conceived and designed the study. NB and SH coordinated the running of the study. NB, TS, SS, SA, EZ, ND and ZT conducted data collection. $N B, S H, W G, W G$, and EZ have participated in data analysis. NB and SH drafted the manuscript. NB, SH, MS, SS, TS, EZ, WG, SA, WG, ND, and ZT contributed to the interpretation of the analysis and critically revised the manuscript. All authors read and approved the final manuscript.

\section{Funding}

Arba Minch University supports this research financially. The university has no role in the design of the study, collection, analysis, and interpretation of the data and in writing the manuscript.

\section{Availability of data and materials}

The data used to support the findings of this study are available from the corresponding author upon request.

\section{Ethics approval and consent to participate}

The letter of ethical approval was obtained from the institutional review board of the College of Medicine and Health Sciences at Arba Minch University with reference number CMHS/1 1833/11. Written consent from all participants was obtained after being fully informed about the objectives and procedures of the study for both groups. The confidentiality and privacy of participants were actively protected. All participants were assigned a unique identification number. Every effort was made to emphasize the voluntariness of this study and decisions to stop or discontinue in the study was respected and did not affect the regular attendance of education in any way.

\section{Consent to publish}

Not applicable.

\section{Competing interests}

The authors declare that they have no competing interests.

\section{Author details}

${ }^{1}$ College of Medicine \& Health Sciences, Department of Public Health, Arba Minch University, Arba Minch, Ethiopia. ${ }^{2}$ College of Medicine \& Health
Sciences, School of Medicine, Arba Minch University, Arba Minch, Ethiopia. ${ }^{3}$ College of Natural Sciences, Department of Biology, Arba Minch University, Arba Minch, Ethiopia. ${ }^{4}$ College of Medicine \& Health Sciences, Department of Nursing, Arba Minch University, Arba Minch, Ethiopia. ${ }^{5}$ Department of Psychology, College of Social Sciences and Humanities, Arba Minch University, Arba Minch, Ethiopia.

Received: 10 September 2019 Accepted: 17 October 2019

Published online: 26 October 2019

\section{References}

1. Yari F, Moghadam ZB, Parvizi S, Nayeri ND, Rezaei E, Saadat M. An evaluation of the effectiveness of a reproductive health education program for nonmedical students in Iran: a quasi-experimental pre-test, post-test research. Shiraz E-Med J. 2016;17(3):e34772.

2. Ministry of Health of Federal Democratic Republic of Ethiopia. National Adolescent and Youth Health Strategy 2016-2020. Addis Ababa: Ministry of Health of Federal Democratic Republic of Ethiopia; 2016.

3. Deyessa N, Tesfaye G. Intention to use condom among students in Agena preparatory school, Guraghe Zone, Ethiopia: with the application of health believe model. Archiv Public Health. 2013;71(1):23.

4. Making Sexual and Reproductive Health and HIV Prevention Information and Services Accessible to Higher Learning Institutions (UNFPA and UNICEF Joint Programme on a Rights-Based Approach to Adolescent and Youth Development) 2008-2013.

5. Prajapati RK, Sharma B, Sharma D. Significance of life skills education. Contemp Issues Educ Res. 2017;10(1):1-6.

6. Melaku YA, Berhane Y, Kinsman J, Reda HL. Sexual and reproductive health communication and awareness of contraceptive methods among secondary school female students, northern Ethiopia: a cross-sectional study. BMC Public Health. 2014;14(1):252.

7. Helleve A, Flisher AJ, Onya H, Mukoma W, Klepp KI. South African teachers' reflections on the impact of culture on their teaching of sexuality and HIV/AIDS. Cult Health Sex. 2009;11(2):189-204.

8. Chandra-Mouli V, Svanemyr J, Amin A, Fogstad H, Say L, Girard F, Temmerman M. Twenty years after International Conference on Population and Development: where are we with adolescent sexual and reproductive health and rights? Adolesc Health. 2015;56(1):S1-6.

9. World Health Organization. Strengthening the health sector response to adolescent health and development. 2018. http://www.searo.who.int/ entity/child_adolescent/topics/adolescent_health/en/. Accessed Sept 17 2018.

10. Gottschalk LB, Ortayli N. Interventions to improve adolescents' contraceptive behaviors in low-and middle-income countries: a review of the evidence base. Contraception. 2014;90(3):211-25.

11. Oljira L, Berhane $Y$, Worku A. Assessment of comprehensive HIV/AIDS knowledge level among in-school adolescents in eastern Ethiopia. J Int AIDS Soc. 2013;16(1):17349.

12. Yibeltal K, Yohannes E. Planning, monitoring and evaluation training manual for higher education HIV/AIDS and SRH interventions in Ethiopia Addis Ababa, Ethiopia. 2013.

13. Agha S, Van Rossem R. Impact of a school-based peer sexual health intervention on normative beliefs, risk perceptions, and sexual behavior of Zambian adolescents. J Adolesc Health. 2004;34(5):441-52.

14. Menna T, Ali A, Worku A. Effects of peer education intervention on HIV/AIDS related sexual behaviors of secondary school students in Addis Ababa, Ethiopia: a quasi-experimental study. Reprod Health. 2015;12(1):84

15. Nicolau Al, Ribeiro SG, Lessa PR, Monte AS, Bernardo EB, Pinheiro AK. Knowledge, attitude and practices regarding condom use among women prisoners: the prevention of STD/HIV in the prison setting. Revista da Escola de Enfermagem da USP. 2012;46(3):711-9.

16. Abera H, Tamiru F, Kibret GD. Intention toward condom use and its associated factors among students of Debre Work Senior Secondary and Preparatory School, East Gojjam Zone, Amhara Region, Ethiopia. HIV/ AIDS. 2017;9:137.

17. De Castro F, Rojas-Martínez R, Villalobos-Hernández A, Allen-Leigh B, Breverman-Bronstein A, Billings DL, Uribe-Zúñiga P. Sexual and reproductive health outcomes are positively associated with comprehensive 
sexual education exposure in Mexican high-school students. PLOS ONE. 2018;13(3):e0193780.

18. Mathews C, Eggers SM, Townsend L, Aarø LE, de Vries PJ, Mason-Jones AJ, De Koker P, Appollis TM, Mtshizana Y, Koech J, Wubs A. Effects of PREPARE, a multi-component, school-based HIV and intimate partner violence (IPV) prevention Programme on adolescent sexual risk behaviour and IPV: cluster randomised controlled trial. AIDS Behav. 2016;20(9):1821-40.

19. Schuster M, Bell R, Berry S, Kanouse D. Impact of a high school condom availability program on sexual attitudes and behaviors (Research summary). Can J Hum Sex. 1998;7(1):69.

20. Van der Geugten J, van Meijel B, den Uyl MH, de Vries NK. Evaluation of a sexual and reproductive health education programme: students' knowledge, attitude and behaviour in Bolgatanga municipality, northern Ghana. Afr J Reprod Health. 2015;19(3):126-36.

21. UN High Commissioner for Refugees (UNHCR), The Sustainable Development Goals and Addressing Statelessness. 2017. https://www.refworld. org/docid/58b6e3364.html. Accessed 6 Oct 2019.

22. Mmbaga EJ, Kajula L, Aarø LE, Kilonzo M, Wubs AG, Eggers SM, de Vries $H$, Kaaya S. Effect of the PREPARE intervention on sexual initiation and condom use among adolescents aged 12-14: a cluster randomised controlled trial in Dar es Salaam, Tanzania. BMC Public Health. 2017;17(1):322.

23. Chen X, Stanton B, Gomez P, Lunn S, Deveaux L, Brathwaite N, Li X, Marshall $S$, Cottrell L, Harris C. Effects on condom use of an HIV prevention programme 36 months post intervention: a cluster randomized controlled trial among Bahamian youth. Int J STD AIDS. 2010;21(9):622-30.

24. Reis M, Ramiro L, de Matos MG, Diniz JA. The effects of sex education in promoting sexual and reproductive health in Portuguese university students. Procedia Soc Behav Sci. 2011;1(29):477-85.

25. Jiang H, Chen X, Li J, Tan Z, Cheng W, Yang Y. Predictors of condom use behavior among men who have sex with men in China using a modified information-motivation-behavioral skills (IMB) model. BMC Public Health. 2019;19(1):261.

\section{Publisher's Note}

Springer Nature remains neutral with regard to jurisdictional claims in published maps and institutional affiliations.
Ready to submit your research? Choose BMC and benefit from:

- fast, convenient online submission

- thorough peer review by experienced researchers in your field

- rapid publication on acceptance

- support for research data, including large and complex data types

- gold Open Access which fosters wider collaboration and increased citations

- maximum visibility for your research: over $100 \mathrm{M}$ website views per year

At BMC, research is always in progress.

Learn more biomedcentral.com/submissions 